\title{
Investigation of Sanitation Aspects among BPL Card Holders of Udaipur District of Rajasthan, India
}

\author{
Noopur Gajraj* and K. L. Dangi \\ Department of Extension Education, RCA, Udaipur, Rajasthan, India \\ *Corresponding author
}

\section{A B S T R A C T}

\section{Keywords}

Sanitation and BPL card holders

Article Info

Accepted:

22 July 2019

Available Online:

10 August 2019
The present study was conducted in Udaipur district of Rajasthan to investigate the sanitation aspects among BPL card holders of Udaipur District. For this 150 respondents were selected and information was collected with the help of structural interview schedule and data was analyzed with the appropriate statistical tools as; Mean Percent Score, Ranking and result were drawn from it. It was found that Sanitation aspects were not being taken care of, problems with latrine, defecation and accessibility for defecation were least taken care and cleaning of toilet was not done in appropriate way by BPL card holders of Udaipur District.

\section{Introduction}

Hygiene, Sanitation and cleanliness are the hallmarks of a civilized society. Sanitation is critical for health and sustainable socioeconomic development. There is an increasing tendency for communities in rural hinterlands to defecate in the open much to the annoyance of officials who are working overtime to deal with different aspects of sanitation with individuals, families and the nation at large. Around the world, South Asia has the largest number of people who have to go to the toilet/defecation outside. In the year 2006, 7 out of 10 people without access to improved sanitation were rural inhabitants. India has a population of almost 1.2 billion people. 55 per cent of this population (nearly 600 million people) has no access to toilets. Most of these numbers are made up by people who live in urban slums and rural areas. According to a recent United Nations study, the entire Indian population has greater access to mobile phones than toilets.

\section{Materials and Methods}

The study was conducted in Kherwara Panchayat Samiti in Udaipur district of Rajasthan which has highest population of BPL card holders. 10 villages near to panchayat samiti headquarter were selected and grouped into four Gram Panchayat viz.; Jawas, Kherwara, Karchha and Bayri. Complete list of BPL card holders of selected villages was prepared. A total of 150 
respondents were selected for investigation. Therefore, proportionate sample from each village was drawn through random sampling technique.

\section{Results and Discussion}

\section{Investigation of sanitation aspects}

The results pertaining to Sanitation aspects of the rural areas covered under the study are presented under the following heads:

Categorization of BPL card holders on the basis of extent of care

The Sanitation aspects were studied in terms that they were taken care of by respondents. As far as the extent of care was concerned, data in table 1 reveal that majority of BPL card holders of area of study comes under high category of extent of care 61 (40.67 per cent). Majority of BPL card holders 22 (81.48 per cent) of Kherwara village comes under high category of the extent of care. On the other hand majority of BPL families of Jawas 18 (33.96 per cent) and Karchha 21 (60 per cent) comes under low category of the extent of care of sanitation aspects. Based on these findings it was concluded that the Sanitation aspects are not being taken care of by most of BPL card holders of Jawas, Bayri and Karchha village.

The current results are well supported by Tiwari (2015), Gowda et al., (2013), Talwar and Kishtwaria (2004) and Jain et al., (2013).

\section{Major aspect wise categorization of extent of care of sanitation aspects}

After categorization of BPL card holders as per their extent of care for Sanitation aspects (Table 1), major aspect wise categorization of them of Sanitation aspects namely Defecation, Mode of Defecation, Cleaning of toilet,
Ventilation in toilet, Accessibility for Defecation, Problems with latrine, Garbage/Human Excreta Disposal and Drainage was done through calculating the MPS acquired about major aspects and ranking them (Table 2).

Analysis of data given in Table 2 reveal that Drainage was the aspects among all Sanitation aspects, being taken care the most (ranked 1 with MPS 81.56) as whole and as we concerned village, Kherwara (MPS 79.01), Bayri (MPS 70.48), Jawas (MPS 69.50), it also taken care the most. Karchha (MPS $66.67)$ is lowest among all villages.

Mode of Defecation, Garbage/Human Excreta Disposal, Cleaning of Toilets, Ventilation in toilet with rank 2,3,4,5 and MPS 78.40, 76.63, $72.11,71.78$ moderately being taken care as whole as well as all village with similar MPS (66.67). Garbage/Human Excreta Disposal, Cleaning of toilet and Ventilation in Toilet taken care most in Kherwara (MPS 66.26, 68.21, 65.43 respectively). Garbage/Human Excreta Disposal taken care least in Bayri (MPS 56.19), Cleaning of Toilet and ventilation in Toilet taken care least in Karchha (MPS 45.00 and 46.67 respectively).

Problems with latrine, Defecation and Accessibility for defecation with rank 8,7,6 and MPS 60.33, 69.61, 71.11 were least taken care by BPL card holders of all village. Problems with Latrine were least taken care in Kherwara (MPS 40.12). Defecation was least taken care in Bayri and Karchha similar MPS 53.01. Accessibility for Defecation was least taken care in Kherwara, Jawas and Karchha similar MPS 55.56.

In view of data (Table 2), it was concluded that Drainage was being taken care the most and problems with Latrine taken care the least by BPL card holders in rural areas of Udaipur district. 
Table.1 Categorization of BPL card holders on the basis of extent of care

\begin{tabular}{|l|l|l|l|l|l|l|l|l|l|l|l|}
\hline S.NO & Category & \multicolumn{2}{|l|}{ Jawas } & \multicolumn{2}{l|}{ Kherwara } & \multicolumn{2}{l|}{ Karchha } & \multicolumn{2}{l|}{ Bayari } & \multicolumn{2}{l|}{ Total } \\
\hline & & f & $\mathbf{\%}$ & $\mathbf{f}$ & $\mathbf{\%}$ & $\mathbf{f}$ & $\mathbf{\%}$ & $\mathbf{f}$ & $\mathbf{\%}$ & $\mathbf{f}$ & $\mathbf{\%}$ \\
\hline $\mathbf{1 .}$ & low(29-34) & 18 & 33.96 & 1 & 3.70 & 21 & 60.00 & 7 & 20.00 & 47 & 31.33 \\
\hline $\mathbf{2 .}$ & medium(34-39) & 18 & 33.96 & 4 & 14.81 & 5 & 14.29 & 15 & 42.86 & 42 & 28.00 \\
\hline $\mathbf{3 .}$ & high(39-44) & 17 & 32.08 & 22 & 81.48 & 9 & 25.71 & 13 & 37.14 & 61 & 40.67 \\
\hline & Total & $\mathbf{5 3}$ & 100 & $\mathbf{2 7}$ & 100 & $\mathbf{3 5}$ & 100 & $\mathbf{3 5}$ & 100 & 150 & 100 \\
\hline
\end{tabular}

Table.2 Major aspect wise categorization of extent of care of sanitation aspects

\begin{tabular}{|c|c|c|c|c|c|c|c|c|c|c|}
\hline \multirow{3}{*}{$\begin{array}{l}\text { SUB } \\
\text { ASPECTS }\end{array}$} & \multicolumn{8}{|c|}{ GRAM PANCHAYAT } & \multirow{2}{*}{\multicolumn{2}{|c|}{ TOTAL }} \\
\hline & \multicolumn{2}{|c|}{ JAWAS } & \multicolumn{2}{|c|}{ KHERWARA } & \multicolumn{2}{|c|}{ KARCHHA } & \multicolumn{2}{|c|}{ BAYRI } & & \\
\hline & MPS & Rank & MPS & Rank & MPS & Rank & MPS & Rank & MPS & Rank \\
\hline Defecation & 52.2 & 7 & 52.78 & 7 & 53.1 & 5 & 53.1 & 7 & 69.61 & 7 \\
\hline Mode of Defecation & 66.67 & 2 & 66.67 & 3 & 66.67 & 2 & 66.67 & 2 & 78.4 & 2 \\
\hline Cleaning of toilet & 55.03 & 6 & 68.21 & 2 & 45 & 7 & 60 & 3 & 72.11 & 4 \\
\hline Ventilation in toilet & 55.35 & 5 & 65.43 & 5 & 46.67 & 6 & 59.05 & 4 & 71.78 & 5 \\
\hline Accessibility for Defecation & 55.56 & 4 & 55.56 & 6 & 55.56 & 4 & 54.92 & 6 & 71.11 & 6 \\
\hline Problems with latrine & 39.62 & 8 & 40.12 & 8 & 38.57 & 8 & 37.62 & 8 & 60.33 & 8 \\
\hline $\begin{array}{l}\text { Garbage/Human Excreta } \\
\text { Disposal }\end{array}$ & 57.44 & 3 & 66.26 & 4 & 56.83 & 3 & 56.19 & 5 & 76.63 & 3 \\
\hline Drainage & 69.5 & 1 & 79.01 & 1 & 66.67 & 1 & 70.48 & 1 & 81.56 & 1 \\
\hline
\end{tabular}

Table.3 Categorization of major aspects of sanitation appropriateness

\begin{tabular}{|c|c|c|c|c|c|c|c|c|c|c|}
\hline \multirow[t]{3}{*}{ ASPECTS } & \multicolumn{8}{|c|}{ GRAM PANCHAYAT } & \multicolumn{2}{|c|}{ TOTAL } \\
\hline & \multicolumn{2}{|c|}{ JAWAS } & \multicolumn{2}{|c|}{ KHERWARA } & \multicolumn{2}{|c|}{ KARCHHA } & \multicolumn{2}{|c|}{ BAYRI } & & \\
\hline & MPS & Rank & MPS & Rank & MPS & Rank & MPS & Rank & MPS & Rank \\
\hline Cleaning of toilets & 58.86 & 4 & 54.07 & 3 & 11.42 & 4 & 27.42 & 4 & 39.6 & 4 \\
\hline Disposal of Waste water & 98.86 & 1 & 98.51 & 1 & 97.14 & 1 & 98.28 & 1 & 98.26 & 1 \\
\hline Disposal of Garbage & 96.98 & 2 & 97.03 & 2 & 95.42 & 2 & 97.71 & 2 & 96.8 & 2 \\
\hline Cleaning of clothes & 62.64 & 3 & 53.33 & 4 & 89.14 & 3 & 714 & & $60 ?$ & 3 \\
\hline
\end{tabular}




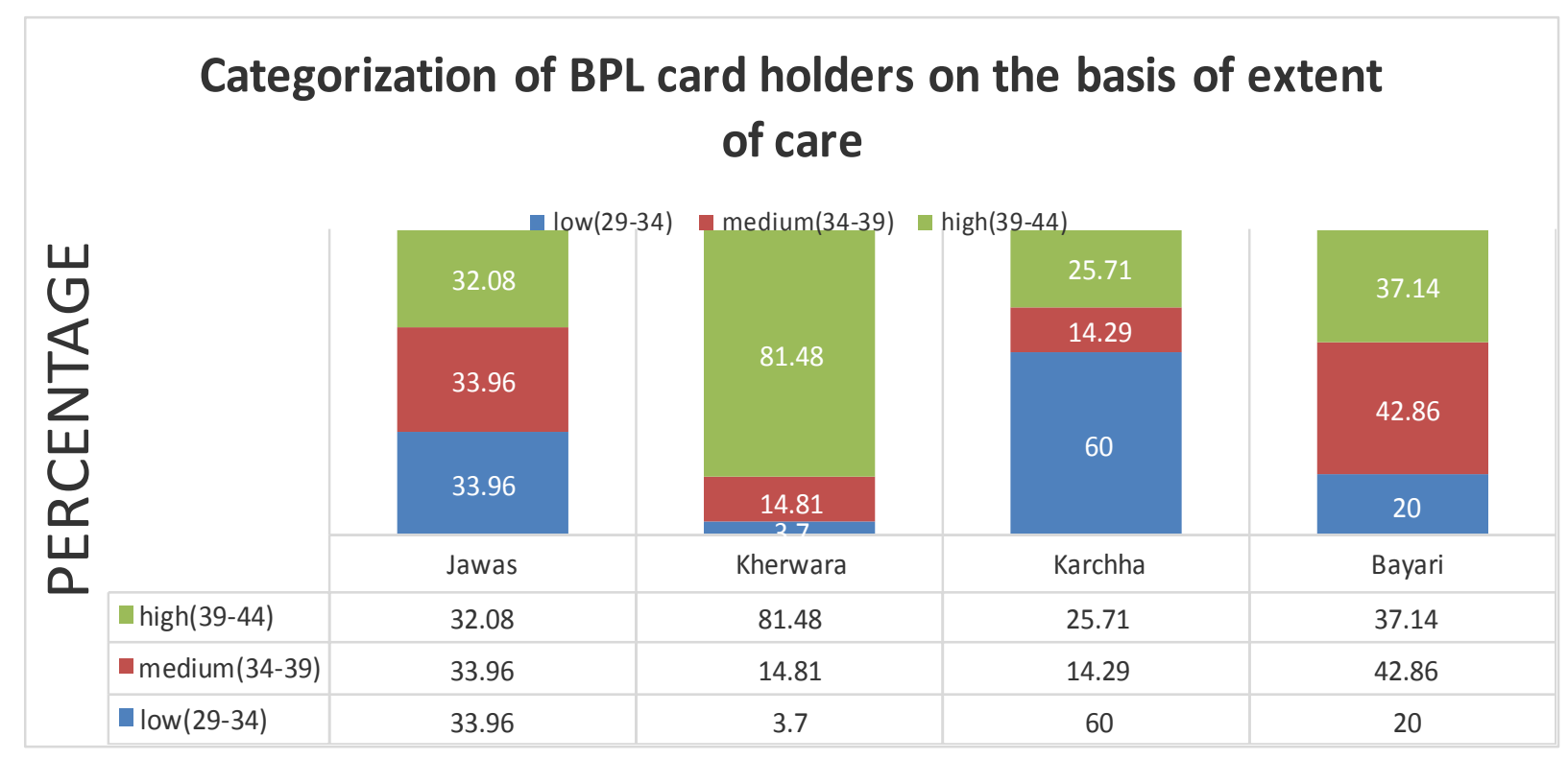

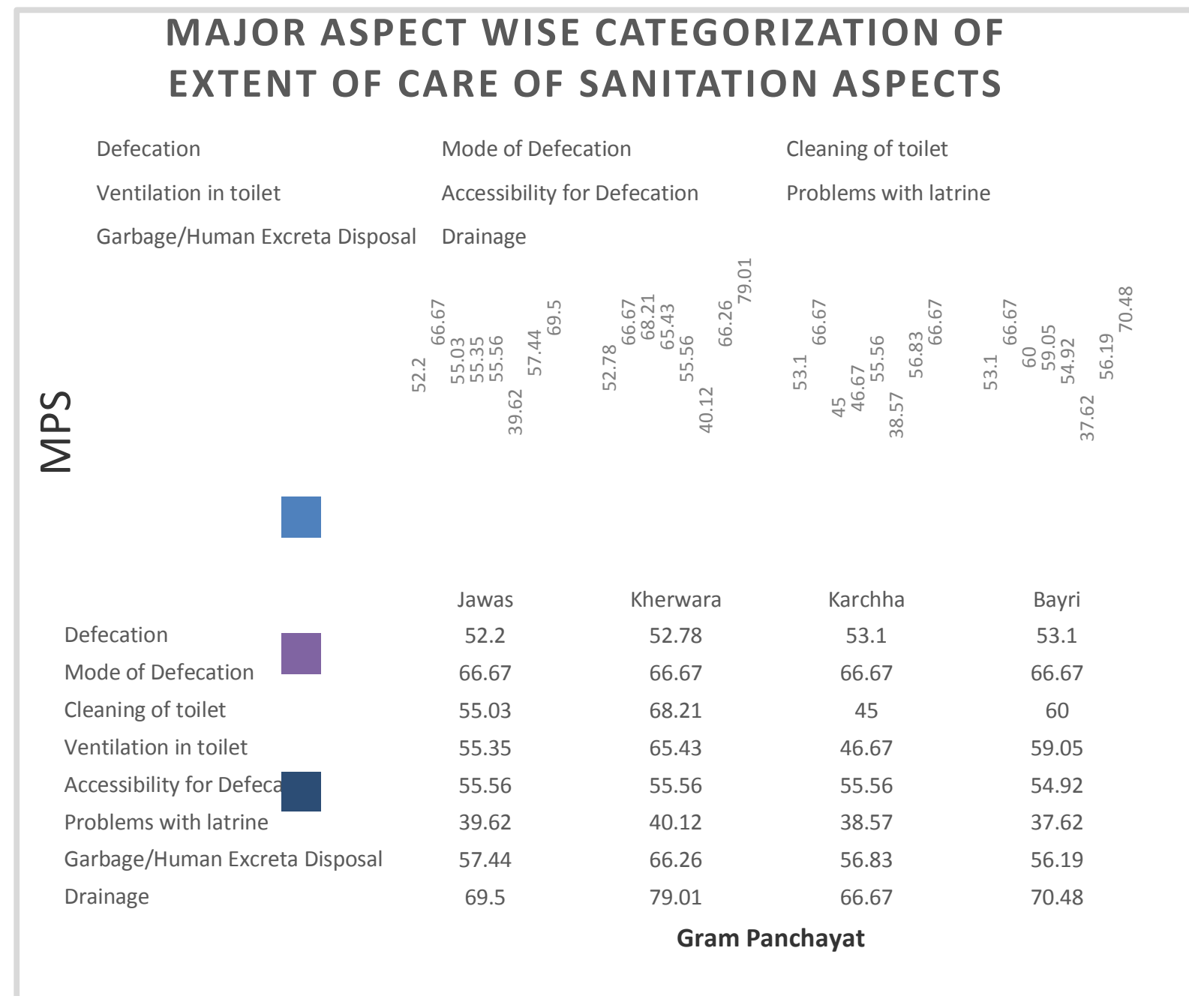




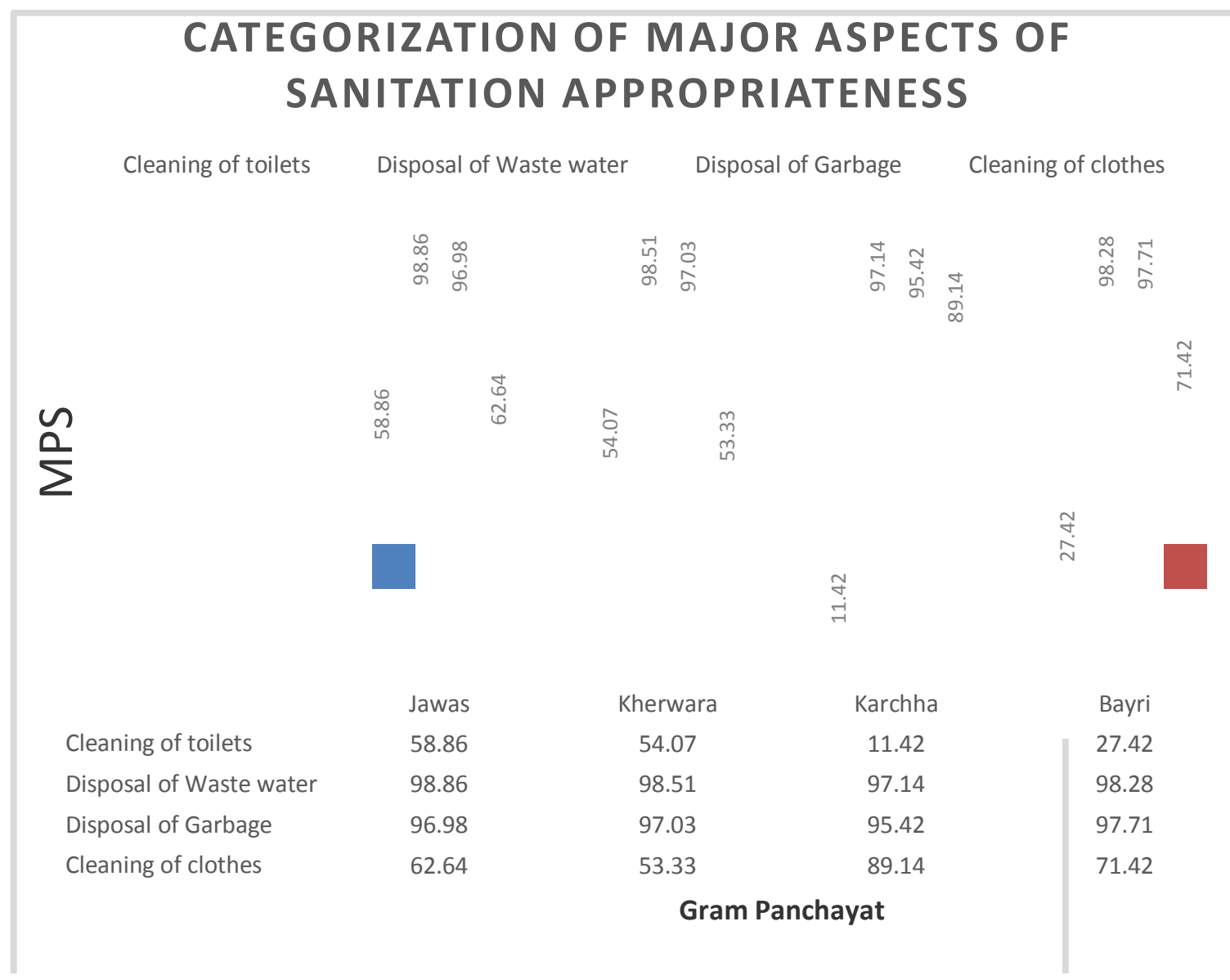

There were problems in latrine, some were chocking some were damaged and most of villagers of karchha gram has no accessibility for defecation, they were still defecated in open which is a major issue. Besides defecation, garbage disposal was also a burning issue in the study area as there was no awareness regarding disposal of human excreta or garbage, people generally dispose the garbage in open which may cause many diseases. So it is recommended that there is a need of awareness program regarding defecation and disposal of human excreta/garbage so that a healthy environment should be created over the area. Past studies of those of Tiwari (2015), Jain et al., (2013), Kumar and Das (2014), Talwar and Kishtwaria (2004), Upadhaya (1998) is similar to the findings of present investigation. Major aspects wise categorization of
Degree of Appropriateness

After categorization of BPL card holders as per their extent of care for sanitation aspects, major aspect wise categorization of sanitation appropriateness was done through calculating the MPS acquired about major aspects viz., Cleaning of toilets, disposal of waste water, disposal of garbage and Cleaning of clothes and ranking them accordingly (Table 3 ).

Analysis of data given in Table 3 reveal that Disposal of waste water was done in most appropriate way (ranked 1 MPS 98.26). Among these four villages, Jawas had highest MPS 98.86 and Karchha had the lowest MPS 97.14. Disposal of Garbage and Cleaning of Clothes were Sanitation aspects which moderately appropriate with their respective 
ranks 2,3 and MPS 96.80, 69.20 respectively. Bayri had highest MPS 97.71 and Karchha had the lowest MPS 95.42. Karchha had highest MPS for cleaning of clothes (89.14), Kherwara had lowest MPS 53.33. Cleaning of Toilet is done least appropriate way (ranked 4 and MPS 39.60). Jawas had highest MPS 58.86 and Karchha had lowest MPS only 11.42. In view of data (Table 3), it is concluded that Disposal of waste water was done in most appropriate way on daily basis while Cleaning of Toilet was done in least appropriate way by BPL card holders in rural areas of Udaipur district. It was observed that cleaning of toilets were not done in appropriate way on daily basis which may cause an unhealthy environment in the family and surrounding so it is recommended that care should be taken in this area by people. Past studies of those of Tiwari (2015), Jain et al., (2013), Kumar and Das (2014), Talwar and Kishtwaria (2004), Upadhaya (1998) is similar to the findings of present investigation.

Majority of BPL card holders of area of study comes under high category of extent of care. Sanitation aspects were not being taken care of by most of BPL card holders of Jawas, Bayri and Karchha village. Drainage was the aspects among all Sanitation aspects, being taken care the most. Mode of Defecation, Garbage/Human Excreta Disposal, Cleaning of Toilets, and Ventilation in toilet was moderately being taken care. Problems with latrine, Defecation and Accessibility for defecation were least taken care by BPL card holders of study area. Disposal of waste water was done in most appropriate way. Disposal of Garbage and Cleaning of Clothes were Sanitation aspects were moderately appropriate. Cleaning of Toilet was done in least appropriate way in study area.

\section{References}

Gowda, K. Chandrashekar, M.N. Sridhara, M.V. Hemalatha, B.N. 2013. Solid Waste Management in the Slums and Squatter Settlements in the City of Bangalore. International Journal of Scientific and Research Publications. 3: 2250-3153.

Jain, S. Middha, R. Kaushik, P. and Juneja, S. K. 2013. A comparative analysis of water and sanitation practices in project and non-project villages of Rajasthan state, India. International Journal of Science and Technology. 8: 461-467.

Kumar, A. Das, K.C. 2014. Drinking Water and Sanitation Facility in India and Its Linkages with Diarrhoea among Children under Five: Evidences from Recent Data. International Journal of Humanities and Social Science Invention. 3: 50-60.

Talwar, N. and Kishtwaria, J. 2004. Awareness for clean and green environment. Social Welfare. 51 (3): 27-30.

Tiwari, S. 2015. Sanitation and hygiene policy of India: towards a new paradigm. International Journal of Advanced Research in Management and Social Sciences. 4: 221-232.

Upadhyay, V. 1998. Gaon Mein Pradushan, Samasya Aur Samadhan, Kurukshetra. 43 (6): 9-10.

\section{How to cite this article:}

Noopur Gajraj and Dangi K. L. 2019. Investigation of Sanitation Aspects among BPL Card Holders of Udaipur District of Rajasthan, India. Int.J.Curr.Microbiol.App.Sci. 8(08): 29562961. doi: https://doi.org/10.20546/ijcmas.2019.808.341 